\title{
Cervical Cancer Screening in an Early Diagnosis and Screening Center in Mersin, Turkey
}

\author{
Tufan Nayir ${ }^{1}$, Ramazan Azim Okyay $^{2 *}$, Ersin Nazlican $^{3}$, Hakki Yesilyurt ${ }^{4}$, Muhsin \\ Akbaba $^{3}$, Berrin Ilhan ${ }^{1}$, Aytekin Kemik ${ }^{1}$
}

\begin{abstract}
Cancer is a major public health problem due to the jeavy disease burden, fatality and tendency for increased incidence. Of all cancer types, cervical cancer is reported to be the fourth most common cancer in women, and the seventh overall, with an estimated 528,000 new cases worldwide in 2012. It features a long preclinical phase with slowly progressing precancerous lesions such as CIN 2 and 3 and adenocarcinoma in situ. Therefore, screening programs such as with Pap smear tests may play an important role in cervical cancer prevention. The purpose of this study was to present results of a Pap smear screening survey for cervical cancer targeting women living in an urban area in the province of Mersin, located in the Mediterranean region of Turkey. This communitybased descriptive study included women living at Akdeniz county of Mersin province. A total of 1,032 screened women between 30 and 65 ages within the routine screening programme constituted the study population. The mean age of the participants was $43.8 \pm 8.6(\mathrm{~min} .30$, max. 65$)$ years. The percentage of the participants who had previously undergone smears was $40.6 \%$. Epithelial cell changes were found in $26(2.5 \%)$ participants, with ASC-US in $18(1.7 \%)$, ASC-H in $2(0.2 \%)$, LSIL in $5(0.5 \%)$ and HSIL in $1(0.1 \%)$. The most common clinical presentation together with epithelial changes was abnormal vaginal discharge. Taking into account the presence of women who had never undergone Pap test; it should be offered at primary level of health care in the form of a community-based service to achieve reduced morbidity and mortality rates.
\end{abstract}

Keywords: Cervical cancer - pap smear - prevention - cancer screening - community

Asian Pac J Cancer Prev, 16 (16), 6909-6912

\section{Introduction}

Cancer is a major public health problem both in Turkey and worldwide due to its disease burden, fatality and tendency for increased incidence (Sahin et al., 2013). Of all cancer types cervical cancer is the fourth most common cancer in women, and the seventh overall, with an estimated 528,000 new cases worldwide in 2012 (Ferlay et al., 2013). The global burden of cervical cancer is disproportionately high among the developing countries where $85 \%$ of the estimated new cases occur (Ali et al., 2012).

On the contrary developed countries have been successful in controlling the incidence of cervix cancer largely due to the widespread and systematic use of the Papanicolaou (Pap) smear test which is an effective, easily applicable, low-cost, harmless and high-sensitive method of early diagnosis, reducing treatment burden, morbidity and mortality (Elovainio et al., 1997). Cervical cancer has a long preclinical detection phase consisting of slowly progressing precancerous lesions such as
CIN 2 and 3 and adenocarcinoma in situ, caused by persistent infection with one of the oncogenic types of HPV, particularly HPV 16 and 18. The precursor lesions may progress to invasive cervical cancer over a period of 1 to 4 decades. Therefore, screening programs such as Pap smear screenings play an important role in cervical cancer prevention (Sankaranarayanan, 2014). Pathological changes in epithelial tissues can be diagnosed with the Pap smear test even when there is no indication (Ozdemir and Bilgili, 2010). The valueof the cervical cancer screening in reducing the risk of cervical cancer and mortality has been firmly established, and it is estimated that regular screening reduces the risk of cancer up to $80 \%$ (Stewart and Kleihues, 2003; Ozgül, 2010).

Being the eighth most common cancer type in terms of both incidence and cause of death, cervix cancer is a remarkable health problem in Turkey which is a country with a young population (Kaya, 2009; Ozgul, 2010). In Turkey, cancer screening activities are mainly being conducted by two health institutions of the Turkish Ministry of Health; by "Early Diagnosis and Screening 
Tufan Nayir et al

Centers for Cancer" (abbreviated as KETEM in Turkish) and by "Mother and Child Care and Family Planning Centers" in the context of the Reproductive Health Program and by means of the polyclinic and clinic activities at the hospitals (Demirhindi et al., 2012).

The purpose of this study is to present the results of a screening survey for cervical cancer targeting women population living in an urban area in the province of Mersin, located at the Mediterranean region of Turkey. The survey also aims to raise population awareness and level of knowledge about cancers besides early diagnosis and cancer prevention.

\section{Materials and Methods}

This community-based descriptive study included women living at Akdeniz county of Mersin province. Akdeniz county is an urban district of Mersin province with a population of 53.277 women between 35-65 ages which is the accepted target population for cervical screening according to national standards for cervical cancer screening (Turkish Ministry of Health, 2009).

A total of 1032 screened women between 30 and 65 ages within the routine screening programme conducted by the Early Diagnosis, Screening and Education Center for Cancer of the Mersin Province (KETEM) constituted the study population.

The study was carried out between January and June 2013. The women in the study group were educated about all types of cancer, but in particular about cervical cancer by the researchers. The local population was also informed about the subject by the help of printed handouts and posters. The names and addresses of women in the study group were listed and home visits were performed to inform them about the study and invite them at the proper time of their menstrual cycle in groups of ten to the KETEM where a room was specifically equipped for cervical smear.

The women who arrived at the KETEM to participate in the study signed an informed consent form after being re-informed and clarified for any question. A questionnaire about personal information, history of reproductive health and physical examination was filled for every woman followed by cervical smear sampling by brushing method at the transformation zone of the cervix according to medical literature (Fiscella and Franks, 1999). The samples obtained and carefully fixed with ethanol were transferred to the cytology laboratory before the end of the official working hours. The maximum attention was paid during the process taking into account that cervix carcinomas were greatly missed due to defects in sampling and evaluation procedures associated with $30 \%$ of the new cases of cervical cancer each year (ACOG, 2009).
The women who did not care about the rules sited below and previously declared at home visits, which were also depicted at the handouts, were not sampled and re-invited for the procedure: 1) A sexual abstinence of at least 48 hours before sampling, 2) No vaginal douching since 24 hours before sampling, 3) No use of any vaginal medication (cream, tablets or any form) since 48 hours before sampling, 4) No menstrual bleeding.

Cytology laboratory reported the examination results according to the Bethesda III classification system (2001). In Bethesda classification smears' cytology abnormalities were classifid under 3 categories: atypical squamous cells (ASC); low-grade squamous intraepithelial lesions (LSIL); and high-grade squamous intraepithelial lesions (HSIL). The ASC category was subdivided into 2 categories: the unknown signifiance category (ASC-US); and the one, which high-grade lesions cannot be excluded (ASC-H) (Apgar et al., 2003).

The data were analyzed by SPSS 11.5 statistical package program.

\section{Results}

The number of women agreed to participate in the

Table 1. Characteristics of Participants Included in the Study

\begin{tabular}{lc}
\hline Charactersitics & \\
\hline Age, mean \pm SD & $43.8 \pm 8.6$ \\
Marital status, $\mathrm{n}(\%)$ & \\
$\quad$ Married & $951(92.2)$ \\
Divorced or widowed & $73(7.1)$ \\
Single & $8(0.7)$ \\
Level of education, $\mathrm{n}(\%)$ & \\
Illiterate & $108(10.5)$ \\
literate & $38(3.7)$ \\
Primary school & $567(54.9)$ \\
High school or further & $320(30.9)$ \\
Smoking, yes, $\mathrm{n}(\%)$ & $255(24.7)$ \\
Alcohol consumption, yes, $\mathrm{n}(\%)$ & $5(0.5)$ \\
Occupation n $(\%)$ & \\
Housewife & $947(91.8)$ \\
Civil cervant & $35(3.4)$ \\
Worker & $10(1.0)$ \\
Other(artisan or self-employed) & $40(3.8)$ \\
\hline
\end{tabular}

Table 2. History and Clinical Presentation of Participants Included in the Study

\begin{tabular}{lr}
\hline History and clinical presentation & \\
\hline Abnormal vaginal discharge, yes, n (\%) & $311(30.1)$ \\
Abdominal pain, yes, n (\%) & $67(6.5)$ \\
Abnormal bleeding, yes, n (\%) & $20(1.9)$ \\
Previously undergone smear, yes, n (\%) & $419(40.6)$ \\
\hline
\end{tabular}

Table 3. Comparison of Epithelial Cell Changes with Other Similar Studies

\begin{tabular}{lcccccc}
\hline Pathology Results & Our Study & Sengul et al. & Mehmetoğlu et al. & TCCRG* & Eroğlu et al. & Öner et al. \\
\hline ASC-US & 1.7 & 1.18 & - & 1.07 & 0.5 & 1.08 \\
ASC-H & 0.2 & - & - & 0.07 & - & - \\
LSIL & 0.5 & 0.39 & 0.6 & 0.3 & 0.2 & 0.36 \\
HSIL & 0.1 & 0.16 & 0.6 & 0.17 & 0.2 & 0.36 \\
\hline *
\end{tabular}

* Turkish Cervical Cancer and Cervical Cytology Research Group 
study was 1032 . The mean age of the participants was $43.8 \pm 8.6$ ( $\min .30$, max. 65) years. The main education level was primary school $(54.9 \%)$, and the majority of participating women were principally unpaid domestic workers $(91.8 \%)$. The characteristics of participants are presented in Table 1.

The most common gynecological symptom in participants was abnormal vaginal discharge with $30.1 \%$. The percentage of the participants who had previously undergone smear was $40.6 \%$. History and clinical presentation of participants included in the study is presented in Table 2.

Epithelial cell changes were found to be in $26(2.5 \%)$ participants with ASC-US in $18(1.7 \%)$, ASC-H in 2 $(0.2 \%)$, LSIL in $5(0.5 \%)$ and HSIL in $1(0.1 \%)$. The most observed clinical presentation together with epithelial changes was abnormal vaginal discharge. In 25 (96.1\%) participants with epithelial changes abnormal vaginal discharge was present. Another remarkable finding is that the $24(92.3 \%)$ of the participants with epithelial changes had primary school or lower education levels. Comparison of epithelial cell changes found in our study with other similar studies is presented in Table 3 .

\section{Discussion}

Cervical cancer is the most widely screened cancer in the world both in high- and middle-income countries. Population-based cervical cytology screening programs offering Papanicolaou testing every 3 to 4 years have reduced cervical cancer incidence and mortality by up to $80 \%$ in developed countries of Europe, North America, Japan, Australia, and New Zealand in the past 5 decades (Stewart and Kleihues, 2003). This has emphasized the key role of effective screening program to detect precancerous lesions that could develop into invasive cancer (IdestrOm et al., 2002; Saraiya, 2003) as in the example of a cervical cancer screening program in Taiwan that achieved a $47.8 \%$ of decrease in the incidence of invasive cervix cancer between 1995 and 2006 (Chen et al., 2009).

The mean age of the participants was 43.8. It is thought that the average age of the women population included in the study was appropriate considering the fact that the most common age to develop cervical cancer is between 40 and 50 years, and its precursor lesions usually occur 5-10 years prior (Banik et al., 2011).

The most observed clinical presentation together with epithelial changes was abnormal vaginal discharge. It is well known that HPV infection, intraepithelial lesions and abnormal vaginal discharge is closely associated (Ojiyi et al., 2013; Vaidya, 2003). As it points out unhealthy cervix, abnormal vaginal discharge sholud not be overlooked (Singh et al., 1992).

In this study, $40.6 \%$ of participants had previously undergone the Pap smear test while in other studies conducted in Turkey have reported a rate of $10 \%$ and $20 \%$ (Demirhindi et al., 2012; Sevil et al., 2013; Karabulutlu, 2013). This might result from the methodological differences between studies. On the other hand in developed countries this rate is near $90 \%$ (Solomon et al., 2007). Conclusively, it seems that the awareness and performance of Turkish women is weaker.

Epithelial cell changes were found to be in $2.5 \%$ of the participants with ASC-US in $1.7 \%$, ASC-H in $0.2 \%$, LSIL in $0.5 \%$ and HSIL in $0.1 \%$ in this study. Sengul et. al (2014) found an overall prevalence of the cytological abnormality $1.83 \%$, with ASCUS in $1.18 \%$, LSIL in $0.39 \%$, HSIL in $0.16 \%$, atypical glandular cells of undetermined significance (AGUS) in $0.07 \%$ and squamous cell carcinoma in $0.02 \%$ in an hospital setting. Mehmetoğlu et al. (2010) reported epithelial cell anomalies in $1.2 \%$ of the cases among them $0.6 \%$ was LSIL and $0.6 \%$ was HSIL in a study performed in 332 married women attending a Family Medicine Clinic in Bursa Province of Turkey in 2010. Turkish Cervical Cancer and Cervical Cytology Group (2009) performed an important study with the participation of 33 healthcare centers including 140334 women for the evaluation of the prevalence of cervical cytological abnormalities in Turkey. Their overall prevalence of cytological abnormality was $1.8 \%$ and prevalence of ASCUS, LSIL, HSIL, and atypical glandular cells (AGC) was $1.07 \%, 0.30 \%, 0.17 \%$ and $0.08 \%$, respectively. Another study performed in Turkey by Eroğlu et al. (2008) among applicants to Konya provincial KETEM (Early diagnosis, screening and education center for cancer) for cervical smear reported cytology results as ASC-US in $0.5 \%$, LSIL in $0.02 \%$ and HSIL in $0.02 \%$. Oner et al. (2004) examined 17 years old and older married women in Doğankent, a semirural area of Adana province, in the Mediterranean region of Turkey and reported epithelial cell changes $1.8 \%$ with ASC-US in $1.1 \%$, LSIL in $0.4 \%$ and HSIL in $0.4 \%$. Comparison of epithelial cell changes with other similar studies carried out in Turkey is highlighted in Table 3. Although there are differences in the findings obtained in these studies, the diversity is likely due to differences in the methodology of the studies. While some of the above-mentioned studies were designed as community-based researches such as ours, in the other studies, participants were chosen among women admitted to the health care providers. In addition, the age groups included in these studies vary. Nevertheless, when compared with studies conducted in the western communities the rates are quite lower in Turkey (Kulig et al., 2006; Duggan et al., 2006).

The 26 participants with abnormal epithelial changes were referred to gynecology outpatient clinics for advanced diagnosis and treatment, where gynecologists who examined the patients performed colposcopies to take cervical biopsies. In one of them, squamous cell carcinoma was detected and total abdominal hysterectomy and bilateral salpingo-oophorectomy operation was performed.

In conclusion, the incidence, mortality, and morbidity of cervical cancer have been reduced by means of early detection of the cervical abnormalities particularly in the developed countries having the regular cervical cancer screening programmes. Cervical cancer screening remains an evolving field with new HPV DNA tests, and development of new technologies. However, Pap smear test is effective, easily applicable, low-cost, harmless and high-sensitive method of early diagnosis, reducing treatment burden, morbidity and mortality, and have been 
Tufan Nayir et al

embraced as the effective population screening method extensively.

Taking into account the presence of women who had never undergone Pap test; it should be offered at primary level of health care in the form of a community-based service. The community should be enlightened about Pap smear test, including its aim, the required frequency of application, by diffuse educational activities, media programs. The aim should be the establishment of a well organized, continuous and community-based cervical cancer screening program; with final conclusion of reduced morbidity and mortality.

\section{References}

ACOG (American College of Obstetricians and Gynecologists) (2009). ACOG practice bulletin. No:109-2009. Obstet Gynecol, 114, 1409-20.

Akgun Sahin Z, Tan M, Polat H (2013). Hopelessness, depression and social support with end of life Turkish cancer patients. Asian Pac J Cancer Prev, 14, 2823-8.

Ali F, Kuelker R, Wassie B (2012). Understanding cervical cancer in the context of developing countries. Ann Trop Med Pub, 5, 3-15

Apgar BS, Zoschnick L, Wright TC Jr (2003). The 2001 Bethesda System terminology. Am Fam Physician, 68, 1992-8.

Banik U, Bhattacharjee P, Ahamad SU, Rahman Z (2011). Pattern of epithelial cell abnormality in Pap smear: A clinicopathological and demographic correlation. Cytojournal, 8, 8 .

Chen YY, You SL, Chen CA et al (2009). Effectiveness of national cervical cancer screening programme in Taiwan: 12-year experiences. Br J Cancer, 101, 174-7.

Demirhindi H, Nazlican E, Akbaba M (2012). Cervical cancer screening in Turkey: A community-based experience after 60 years of Pap smear usage. Asian Pac J Cancer Prev, 13, 6497-500.

Duggan MA, Khalil M, Brasher PM, Nation JG (2006). Comparative study of the thinprep pap test and conventional cytology results in a canadian cohort. Cytopathology, 17, 73-81.

Elovainio L, Nieminen P, Miller AB (1997). Impact of cancer screening on women's health. Int J Gynaecol Obstet, 58, 137-47.

EroGlu C, Unlu Y, Eryılmaz MA, GOnenc O (2008). Konya egitim ve araştırma hastanesi Kanser Erken Teshis-Tarama ve Eğitim Merkezi servikovajinal smear tarama deneyimi (Cervicovaginal smear screening experience early cancer diagnosis-screening and education center konya education and research hospital). Jinekoloji-Obstetrik ve Neonatoloji Dergisi. Mart 2008.

Ferlay J, Soerjomataram I, Ervik M, et al (2014). GLOBOCAN 2012 v1. 0, Cancer Incidence and Mortality Worldwide: IARC CancerBase No. 11. Lyon, France: International Agency for Research on Cancer; 2013. Visit: http://globocan. iarc.fr.

Fiscella K, Franks P (1999). The adequacy of Papanicolaou smears as performed by family physicians and obstetriciangynecologists. J Fam Pract, 48, 294-8.

IdestrOm M, Milsom I, Andersson-EllstrOm A (2002). Knowledge and attitudes about the pap-smear screening program: a population-based study of women aged 20-59 years. Acta Obstet Gynecol, 81, 962-7.

Karabulutlu O (2013). Evaluation of the Pap smear test status of Turkish women and related factors. Asian Pac J Cancer
Prev, 14, 981-6.

Kaya M (2009). Halk sagligi yaklasimiyla servikal kanser (Cervical Cancer with Public Health Perspective) (Ed. Akın A.) HÜKSAM Yayınları, Ankara.

Kulig B, Łukaszek S, Brucka A, et al (2006). [Comparative analysis of abnormal Pap smear and the results of histopathological examination of specimens from the cervix of the programme in-depth diagnosis cervical cancer conducted at the of Operational Gynecology Department ICZMP in Lodz]. Ginekol Pol, 81, 828-33.

Mehmetoğlu HC, Sadıkoğlu G, Ozçakır A, Bilgel N (2010). Pap smear screening in the primary health care setting: a study from Turkey. N Am J Med Sci, 2, 467-72.

Ojiyi E, Dike IE, Okeudo C, Ejikem C, Nzewuihe A, Agbata A (2013). Local risk factors in genital human papilloma virus infection in cervical smears. Ann Med Health Sci Res, 3, 529-35.

Ozdemir O, Bilgili N (2010). Knowledge and practices of nurses working in an education hospital on early diagnosis of breast and cervix cancers. TAF Prev Med Bulletin, 9, 605-12.

Oner S, Demirhindi H, Erdogan S, Tuncer I, Akbaba M (2004). Gynecologic examination fidings and Pap smear screening results of women in Doğankent, Turkey. Turkish J Public Hlth, 2, 85-91.

Ozgul N (2010). The state of cervical cancer in turkey and cervical cancer screening studies. in: cancer control in Turkey (Eds.Tuncer AM (chief), Ozgul N, Olcayto E, Gultekin M). Republic of Turkey, Ministry of Health, 777, 379-84.

Sankaranarayanan R (2014). Screening for cancer in low- and middle-income countries. Ann Glob Health, 80, 412-7.

Saraiya UB (2003). Preventable but not prevented: the reality of cervical cancer. J Obstet Gynaecol Res, 29, 351-9.

Sengul D, Altinay S, Oksuz H, Demirturk H, Korkmazer E (2014). Population-based cervical screening outcomes in Turkey over a period of approximately nine and a half years with emphasis on results for women aged 30-34. Asian Pac $J$ Cancer Prev, 15, 2069-74.

Sevil S, Kevser O, Aleattin U, Ozlem D (2013). The frequency of having pap-smear tests among women between 15-64 years old and the evaluation of the level of their knowledge. J Pak Med Assoc, 63, 873-7.

Singh V, Sehgal A, Luthra UK (1992). Screening for cervical cancer by direct inspection. British Medical Journal, 304, 534-5.

Solomon D, Breen N, McNeel T (2007). Cervical cancer screening rates in the United States and the potential impact of implementation of screening guidelines. CA Cancer $J$ Clin, 57, 105-11.

Stewart BW, Kleihues P (Eds) (2003). Cancers of the female reproductive tract. World Cancer Report, IARC and WHO. IARC Press, Lyon, France. [http://www.scribd. com/doc/2350813/World-Cancer-Report-2003-Stuart-eKleihues-WHO-e-IARC] Last accessed: 15 February 2015.

Turkish Cervical Cancer And Cervical Cytology Research Group (2009). Prevalence of cervical cytological abnormalities in Turkey. Int J Gynaecol Obstet, 106, 206-9.

Turkish Ministry of Health (2009). Kanser erken teşhis, tarama ve eğitim merkezi el kitabı (national (turkish) handbook for early diagnosis, screening and education center for cancer) (2009) [http://kanser.gov.tr/Dosya/Bilgi-Dokumanlari/ ketem-el-kitabi.pdf] Last accessed: 18 February 2015.

Vaidya A (2003). Comparison of Pap test among high and nonhigh risk female. Kathmandu Univ Med J (KUMJ), 1, 8-13 